\title{
Analysis of the information in mandatory reporting in victims of gender violence
}

\author{
Belen Reynaldos, Faustina Sánchez-Rodríguez, Isabel Legaz, Eduardo Osuna \\ Department of Forensic Medicine, School of Medicine, University of Murcia, Murcia, Spain
}

\begin{abstract}
Significance for public health
Violence against women is now widely recognized as a worldwide serious violation of human rights, with important consequences for women's physical, mental, sexual, and reproductive health. On many occasions, violence goes unreported. Emergency departments are often the first point of access to health services for women experiencing gender violence and the healthcare professional plays a key role in the diagnosis and treatment of a situation of violence that are not declared. The report issued when there is a situation of suspected gender violence, contains information that will be transcendent for knowing the circumstances that surround the violence that abuse causes. In this study we found serious deficiencies in the injury report so the information does not conform to the legal requirements needed in a document of such extraordinary importance. Efforts are needed to raise awareness among health professionals about the importance of providing the correct information.
\end{abstract}

\begin{abstract}
The healthcare professional plays a key role in the detection and subsequent channeling of a situation of violence to a judicial level for appropriate investigation. The mandatory reporting of gender violence has become a controversial issue among health care practitioners and victims. The objective of this study was to analyze the quality of the way in which injury reports on victims of gender violence is completed, through an analysis of the information they include, the readability and the degree to which the document can be understood. A retrospective study in a sample of 197 injury reports were performed from health services (primary care, hospital services and emergency services). We analyzed 22 variables related to the content, readability of the document, the victim's identification data as well as identification of the doctor responsible for assistance, the moment of assistance and the characteristics of the injury. The most frequent deficiencies in the data are identification of the doctor responsible for medical attention, the date on which the aggression occurred, a description of the injuries and the judgment of compatibility between the cause of injury (according to the victim) and the actual injury they have. The injury reports do not conform to the legal requirements needed in a document of such extraordinary importance. Greater awareness in health professionals concerning the importance of the injury report as a medicolegal document is needed so that the correct information can be provided to the relevant judicial authority.
\end{abstract}

\section{Introduction}

Violence against women is now widely recognized as a serious violation of human rights, and a global public health problem with important consequences for women's physical, mental, sexual, and reproductive health. ${ }^{1,2}$ It affects women throughout the world, and crosses cultural and economic boundaries. The WHO estimates that, worldwide, $30 \%$ of women aged 15 years and older have experienced physical and/or sexual intimate partner violence and $7 \%$ of women worldwide have experienced non-partner sexual assault. 3,4

Gender violence affects women for the mere fact that they are women and undermines the principle of equality and respect for human dignity and personal freedom. Article 1 of the Declaration on the Elimination of Violence against Women, drafted in the 1993 Vienna Conference, organized by the United Nations (UN), defines the term violence against women as any act of genderbased violence that results in, or is likely to result in, physical, sexual or psychological harm or suffering to women, including threats of such acts, coercion or arbitrary deprivation of liberty, whether occurring in public or in private life.

In the report of the Fourth World Conference on Women, celebrated in 1995 in Beijing, the UN stated that violence against women is an obstacle to achieving the goals of equality, development and peace and violates and impairs human rights and fundamental freedom. The Organization itself defines it as a manifestation of the historical inequality between men and women in power relations. Therefore, this situation constitutes a prominent social challenge that requires the implementation of multidisciplinary and interinstitutional measures.

The 49th World Health Assembly of the World Health Organization (WHO) declared violence as the leading worldwide public health problem and focused on the increase in the incidence of injuries to women. Violence against women in the form of intimate partner violence is costly in terms of economic cost and health. ${ }^{5}$ Violence against women is a social and public health problem because of the magnitude and negative effects in different cultural, social, and economic contexts, with immediate, irreversible and cumulative effects on the welfare, health, quality of life and development of those who suffer it. Because violence crosses many domains, collaboration across different sectors, disciplines, and professions is critical both to fully understand the problem and effectively act to prevent it. ${ }^{6}$ Zerbo et al. ${ }^{7}$ emphasise the importance of setting up a system of integrated services for the suitable management of victims of violence. The integrated intervention of social and health services, including social agencies, legal authorities and medical staff would improve care for the victims.

Emergency departments are often the first point of access to health services for women experiencing gender violence. ${ }^{7-10}$ Many health professional associations have published clinician guidelines on how to identify and respond to victims, ${ }^{11,12}$ according to national health policies. When attending a possible victim of gender violence, the healthcare professional plays a key role in the detection and subsequent channeling of a situation of violence - 
which on many occasions go unreported - to a judicial level for appropriate investigation.

The mandatory reporting of gender violence has become a controversial issue among health care practitioners and victims. ${ }^{13-15}$ This is a complex ethical, moral and legal issue. In Spain physicians are obliged to report acts of domestic violence to the judicial authority, regardless of whether or not they believe that reporting the violence is in the patient's best interest. The doctor, whenever they attend a person presenting a lesion, must complete a report containing information on the date of medical assistance and a description of the injuries (number of injuries, location, possible mechanism of production) and other data of interest that allow their severity and treatment to be understood. This information is communicated to the judicial authority.

On occasions the victim does not wish to report the event and mandatory reporting becomes controversial because of concerns about infringing on women's autonomy and privacy. However, through this injury report, professionals inform the judge about the characteristics of the injuries and the suspected way of infliction, so that forensic inquiry can clarify the reality of what happened. Therefore, the injury report needs to be completed fully and accurately.

The objective of this study was to analyze the quality of the way in which injury reports on victims of gender violence is completed, through an analysis of the information they include, the readability and the degree to which the document can be understood.

\section{Design and Methods}

We conducted a retrospective study in a sample of 197 injury reports selected at random from the total number of reports completed and submitted to the judge by various health services (primary care, hospital services and emergency services) from Murcia (Spain) during 2017 after attending a victim of gender violence $(\mathrm{N}=392)$.

The study was conducted in compliance with the ethical standards of research according to the legal requirements necessary for its development, treating data with strict confidentiality in accordance with the provisions of Regulation (EU) 2016/679, 27 of April, on the protection of natural persons with regard to the processing of personal data and the free movement of such data, with regard to both confidentiality and the custody of the information, preventing any person that does not belong to the research team from making use of it.

In total we analyzed 22 variables related to the content, readability of the document, the victim's identification data as well as identification of the doctor responsible for assistance, the moment of assistance and the characteristics of the injury.

All data was coded for statistical analysis using the IBM SPSS Statistics version 19.0 software. Descriptive statistics were applied calculating the frequencies and percentages for dichotomous and qualitative variables, and the mean, standard or typical deviations, maximum and minimum values for the variable age, the only quantitative variable. Also, an inferential analysis was performed to ascertain the degree of correlation (Pearson statistic) or of association between variables (the $\chi^{2}$ analysis), with statistical significance established for values of $\mathrm{P} \leq 0.05$.

\section{Results}

In $12.6 \%$ of cases it was not possible to identify the centre or service that first attended the victim, being illegible in $3.0 \%$ and not mentioned in $9.6 \%$ of the reports. In $47.2 \%$ of cases the victim was attended by ambulance crew, $26.9 \%$ in hospital emergency departments and $13.2 \%$ in health centres (Table 1).

In $9.1 \%$ of the cases, the age of the victim was not specified in the injury report nor was the date of birth of the woman attended by the doctor. After the analysis of those documents in which they were included, we observed that the average age of the sample of victims was $34.5 \pm 0.8$ (SD. 11.9 years) with a range of 16 to 71 years. By age group, women between 21 and 30 years old $(27.9 \%)$ and between 31 and 40 (26.9\%) predominated (Table 2). As regards the nationality of the victims $59.9 \%$ of the women were of Spanish nationality and $40.1 \%$ of a different nationality.

The date of attending the patient could not be determined in $11.7 \%$ of the studied cases (not appearing in $7.1 \%$ of cases and illegible in $4.6 \%$ of cases). When analysing the number of days that had passed since the date on which the injury took place and health assistance was given, it was seen that $24.9 \%$ of the women went to the emergency department on the same day and $6.1 \%$ on the following day. In $59.9 \%$ of cases it was not possible to establish this interval since information referring to one of these dates was either missing or illegible. On the rest of the occasions (9\%) victims sought medical attention after two or more days (Table 3).

The doctors' identification code was not included in $23.9 \%$ of the documents and illegible in $6.1 \%$. Neither was the name and surname of the person responsible for medical assistance provided in $34.5 \%$ of cases, and it was illegible on $5.6 \%$ of occasions. The victims could not be identified in $7.1 \%$ of cases since the name and surname of the victim did not appear in $3.0 \%$ of cases and it was illegible in $4.1 \%$ of cases. The identification number (National Identification Document) was not included in $33.0 \%$ of the analysed reports and in $62.9 \%$ of cases it was illegible.

Table 1. Frequencies concerning place of first attendance.

\begin{tabular}{lcc} 
& Frequency & Percentage \\
Not available & 19 & 9.6 \\
Illegible & 6 & 3.0 \\
\hline Primary care & 26 & 13.2 \\
Hospital A\&E department & 53 & 26.9 \\
\hline Emergency services & 93 & 47.2 \\
Total & 197 & 100.0 \\
\hline
\end{tabular}

Table 2. Frequency per age group.

\begin{tabular}{lcc} 
& Prequency & Percentage \\
Not available & 18 & 9.1 \\
11-20 years old & 22 & 11.2 \\
\hline 21-30 years old & 55 & 27.9 \\
31-40 years old & 53 & 26.9 \\
\hline 41-50 years old & 31 & 15.7 \\
51-60 years old & 12 & 6.1 \\
61-70 years old & 5 & 2.5 \\
Older 71 years old & 1 & 0.5 \\
Total & 197 & 100.0 \\
\hline
\end{tabular}


It was impossible to know the victim's account of what had happened in $24.9 \%$ of cases (in $18.8 \%$ of cases it was not included and in $6.1 \%$ of cases it was illegible). It should be noted that on $74.1 \%$ of occasions, women mentioned being beaten, while in the rest of cases there was no mention of this word or of the mechanism by which they received their injuries. In their declaration, $19.2 \%$ of women commented that the violence had occurred unexpectedly, 39.0\% after an argument, 7.5\% associated it with alcohol consumption and $2.1 \%$ of cases that it happened for reasons of jealousy.

In the injury report, the type of aggression that the victim had suffered could not be determined in $13.2 \%$ of cases, the number of aggressions was not mentioned determined in $37.5 \%$ of cases and the location of the injury was unclear in $15.2 \%$ of cases (not included in $7.6 \%$ and illegible in $7.6 \%$ of the cases studied).

As to where the aggression took place, it was not possible to know in $67.5 \%$ of cases (in $61.4 \%$ of the injury reports this information does not appear and in $6.1 \%$ of the cases it is illegible). The most common place of the aggression $(22.3 \%)$ was the house in which victim and aggressor lived together, while $4.6 \%$ of aggressions occurred in the street (Table 4).

When analysing the results obtained in the injury report it was impossible to know whether the mechanisms mentioned as the cause of the injuries and the injury observed by the doctor were compatible in $95.4 \%$ of the cases (it does not appear in $89.9 \%$ of cases and is illegible in $5.6 \%$ of the injury reports).

In an analysis of the centres to which the doctor filling in the report belonged, significant differences existed between the centre and the inclusion of identity data of the doctor responsible for the assistance $(P=0.000)$. In this sense, we observe that it is not possible to know the identity in $70.2 \%$ of the reports issued by emergency services, $2.1 \%$ in primary attention and $2.1 \%$ in hospital A\&E departments (emergency department or casualty).

\section{Discussion}

Gender violence is one of the greatest problems for public health, and one in which detection and the way in which the problem is approached by the healthcare professional is decisive, not only for the resolution of the case, but to avoid the repeat of violence that could even lead to the death of the victim. The emergency department has been acknowledged as a place where women with injuries as a result of violence may seek help, being the third choice after friends/family and police. ${ }^{16}$ A positive screening for gender violence is determinant for developing an adequate plan of care. $^{17}$

Simple direct questioning in a supportive environment is effective in facilitating disclosure and hence detecting cases of abuse. ${ }^{8}$ Disclosure of gender violence should take place in a supportive environment and the patient should be encouraged to develop supportive networks. ${ }^{18,19}$ Women receiving care in the emergency department want all their needs to be identified and to have the opportunity to address their children's needs, and explore safety, options, and be given referrals. ${ }^{20}$

It is common for the victim to ask the doctor in attendance not to report the violence to the judicial authorities. ${ }^{21}$ Several studies have analysed women's opinions and preferences about mandatory reporting. Caralis and Musialowskie ${ }^{22}$ interviewed 406 female patients in a medical center. Of these patients, $79 \%$ agreed that physicians should report abuse, findings that did not differ between abused and non-abused women. In a sample of women enrolled in a health maintenance organization, Gielen et al. ${ }^{23}$ found that more than one half of the abused women $(53.7 \%)$ preferred a policy under which reporting abuse is the woman's decision. The loss of autonomy inherent with mandatory reporting, as discussed in the literature, ${ }^{21,24}$ and mandatory reporting seems to be a barrier to disclosure, suggesting that fear may have been the reason the abused women interviewed had not discussed the abuse with their health care provider. ${ }^{23}$

Health service personnel should make women aware of the need for them to file an official complaint and permit the subsequent report to be forwarded to the courts. If the victim refuses but there are grounds for assuming there is a real threat to the physical or psychological integrity of the victim, the health professional should file the official complaint. In this respect, we abide by the legislation concerning patient autonomy, whereby one of the limits of informed consent is established when there is an immediate grave risk to the physical and psychological integrity of the person being attended and it is not possible to obtain authorisation. Unfortunately, there have been cases in which the doctor has not suspected such grave danger, resulting in the death of the victim.

Injuries are an important pathology in health assistance and on many occasions the victim hides their existence or related aspects with its aetiology or mechanisms of production. Thus, the health care professional performs a fundamental role in the detection of situations of violence that are not declared. The injury report is a document of great relevance for the forensic and judicial investigation. The reason for injury reports is to give the judicial authority precise and clear information as regards the injuries that may be the basis for a criminal investigation. ${ }^{25}$ The report provides the judicial authority with the information from the medical examination. As we mention above, complete information and the correct writing up of the document given to the court is of great impor-

Table 3. Frequencies for number of days since violence and visiting doctor.

\begin{tabular}{lcc} 
& Frequency & Percentage \\
Not available & 106 & 53.8 \\
Illegible & 12 & 6.1 \\
\hline Same day & 49 & 24.9 \\
Following day & 12 & 6.1 \\
\hline 2 days later & 4 & 2.0 \\
3 days later & 5 & 2.5 \\
\hline d days later & 5 & 2.5 \\
5 days later & 2 & 1.0 \\
\hline days later & 1 & 0.5 \\
7 days later & 1 & 0.5 \\
Total & 197 & 100.0 \\
\hline
\end{tabular}

Table 4. Frequencies of place where violence occurred.

\begin{tabular}{lcc} 
& Frequency & Percentage \\
Not available & 121 & 61.4 \\
Illegible & 12 & 6.1 \\
\hline Street & 9 & 4.6 \\
Emergency room & 1 & 0.5 \\
\hline Car & 3 & 1.5 \\
Home & 44 & 22.3 \\
Home of supposed aggressor & 7 & 3.6 \\
Total & 197 & 100.0
\end{tabular}


tance. The report issued when there is a situation of suspected gender violence, contains information that will be transcendent for knowing the circumstances that surround the violence that abuse causes. Both judicial measures and measures to prevent new aggressions can be based on this information. When the violent situation is not known or correctly identified, it is impossible to provide the victim with information on prevention, safety planning, options for leaving the abuse, and community resources available. ${ }^{23}$ Moreover, filling the injury report may throw light on the mechanisms involved and may uncover situations that were not initially reported and which form part of the sad percentage of hidden phenomena that characterise this kind of violence.

From a socio-demographic point of view, the victims were predominantly middle aged (average age of 34 years), but with a wide range of between 16 and 71 years, most being in the age group of $21-30(27.9 \%)$ and $31-40(26.9 \%)$. Of the total, $40 \%$ of victims were non-Spanish, which indicates that any woman, independently of their cultural surroundings in which they live can be a victim of gender violence. For Hirt et al. ${ }^{26}$ in certain surroundings and contexts, such as immigration, there may exist erroneous patterns of tolerance towards situations of gender violence on the part of males. However, as mentioned above, gender violence is a global phenomenon and the language of violence is a universal language in which there are no differences between cultural, educational and socio-economic levels. The fact is that gender violence is more visible at the lower levels of society because as we ascend the social ladder, the means to hide these problems increase in an attempt to avoid the disrepute that may befall those involved.

Our study identifies serious deficiencies in the information that the injury reports include and in the description of the injuries they present and the mechanism that originated it. Of particular concern is that in $15.7 \%$ of cases it is not possible to know the extent of the injuries, or to learn of any complementary explorations and other data of interest - in short, the gravity of the aggression - making it difficult for any subsequent expert evaluation by the forensic doctor or any judicial evaluation on the part of the judge.

In a substantial number of documents, it is not possible to identify the doctor responsible for the assistance, since in $23.9 \%$ of cases the identification code was lacking and in $34.55 \%$ of cases so were the name and surname. This information from a judicial point of view is essential since it makes it possible for the doctor responsible first attending the victim to be summoned by the judge to clarify facts and answer questions related to the injury report, which is especially important in those cases where there may be discrepancies. ${ }^{27}$ It is also of note that identifying the victim was not possible in $7.1 \%$ of cases, since in $3 \%$ of cases the data was not included and in $4.1 \%$ it was illegible.

Information on the violent acts that motivated the injury of the victim is of great legal value. We must not forget that the purpose of passing the injury report to the judge is that the health professional concerned, according to their medical knowledge, gives the judge information that will allows them to judge the case, define the magnitude of the crime, the possible responsibility and the urgency or not in any intervention. In our study we also observed an important lack of information on these subjects in the injury reports. In $18.8 \%$ of the reports no information about the facts that motivated medical assistance appeared, in $40.1 \%$ no information was presented other than that the woman says to have been beaten and in $20.8 \%$ the origin of the injuries did not appear. In $61.2 \%$ of cases the location of where the injury occurred and in $51.8 \%$ the date on which the injury took place were not indicated.

The lack of information could be due to the fact the patient did not facilitate that information, since, in many cases of gender violence, women are afraid of saying that they have been a victim of maltreatment, for example by hiding the real origin of the injury by saying that they suffered an accident. Therefore, data as simple as the location or the number of injuries can make it possible to differentiate between an accidental event and a beating, since when someone trips, injuries tend to appear in the exterior part of the extremities and not on the inside part. Regarding the description of the injuries, the information that appears in the analysed documents is equally deficient in a considerable percentage of the same. In this sense, we must highlight that the type of injury was not defined in $5.6 \%$ of cases, the location was not included in $7.6 \%$ and the number of injuries not specified in $29.9 \%$. In agreement with the studies of Sarrión et al. ${ }^{28}$ when describing injuries, there may be a good description of their type and location, but little information regarding the number of injuries.

An aspect that must be taken into account is that in the diagnosis section of the report, $64.5 \%$ made no explicit reference to the observed injuries that would allow conclusions to be reached concerning the mechanism and circumstances in which the facts developed, and therefore to learn about the aetiology of the injuries. It is very striking that in $89.9 \%$ of the reports there is no judgement on the compatibility of the injuries and the mechanism of production described by the victim. These data suggest the need for greater awareness in health professionals on the importance of filling in injury reports in cases of gender violence, with emphasis on aspects of great importance such as the sections referring to the description of injuries, diagnosis, treatment, prognosis, plan of action and any opinion of the compatibility of facts. Our results coincide with those obtained in studies of child abuse, ${ }^{29-30}$ which highlight the deficiencies in the content of injury reports, especially the information related to the description of injuries, the date and time at which the incident took place and any reference to previous aggression, as well as the psychological state of the victim.

The present study is based on a wide sample of injury reports from the victims of gender violence and should be taken into account for immediate application of the steps proposed in order to improve the detection of violence and develop an adequate plan of intervention.

\section{Conclusions}

The implementation of standardized protocols may facilitate the management of health care and support for the victims of violence, although this needs to be accompanied by training for health care professional in emergency care. ${ }^{12}$

We consider the results obtained to be of concern, since they do not conform to the legal requirements needed in a document of such extraordinary importance. The judicial act must focus on requesting the health professional for the information needed, demanding the information that must be given and any complementary information that may be relevant for the medical-legal and judicial investigation. The most frequent deficiencies in the data are identification of the doctor responsible for medical attention, the date on which the aggression occurred, a description of the injuries and the judgment of compatibility between the cause of injury (according to the victim) and the actual injury they have.

Greater awareness in health professionals concerning the importance of the injury report as a medicolegal document is needed so that the correct information can be provided to the relevant judicial authority. 
Correspondence: Eduardo 0suna, Department of Forensic, School of Medicine, University of Murcia, Murcia, E-30100. Spain.

Tel.: +34.868889362 - Fax: +34.868883956 .

E-mail: eosuna@um.es

Key words: gender violence, injury, diagnosis, emergency care, mandatory reporting.

Contributions: BR contributed to the conception and design of the study, acquisition of the data, statistical analyses and interpretation of the data, drafting of the manuscript, and gave final approval for submission of the manuscript. FSR contributed to the conception and design of the study, drafting of the manuscript, and gave final approval for submission of the manuscript. IL contributed to the interpretation of the data, drafting of the manuscript, and gave final approval for submission of the manuscript. EO contributed to the conception and design of the study, interpretation of the data, drafting of the manuscript, and gave final approval for submission of the manuscript.

Conflict of interest: the authors declare no potential conflict of interest.

Funding: none.

Received for publication: 27 July 2018.

Revision received: 26 September 2018.

Accepted for publication: 22 November 2018.

(C) Copyright B. Reynaldos et al., 2018

Licensee PAGEPress, Italy

Journal of Public Health Research 2018;7:1443

doi:10.4081/jphr.2018.1443

This work is licensed under a Creative Commons Attribution NonCommercial 4.0 License (CC BY-NC 4.0).

\section{References}

1. Campbell J. The health consequences of intimate partner violence. Lancet 2002; 359:1509-14.

2. Garcia-Moreno C, Jansen H, Ellsberg M, Heise L, Watts CH, WHO Multi-country Study on Women's Health and Domestic Violence against Women Study Team. Prevalence of intimate partner violence: findings from the WHO multi-country study on women's health and domestic violence. Lancet 2006;368:1260-9.

3. United Nations General Assembly. Declaration on the Elimination of Violence Against Women. A/RES/48/104. Geneve: United Nations; 1993.

4. Abrahams N, Devries K, Watts C, et al. Worldwide prevalence of non-partner sexual violence: a systematic review. Lancet 2014;383:1648-54.

5. Krug EG, Mercy JA, Dahlberg LL, Zwi AB. The world report on violence and health. Lancet 2002;360:1083-8.

6. Mercy JA. Global violence prevention: The time is now. Am J Prev Med 2016;50:660-2.

7. Zerbo S, Milone L, Scalici E, et al. Medico legal procedures related to sexual assault: a 10-year retrospective experience of a Daphne protocol application. Egyp J Forens Sci 2018;8:4.

8. Olive P. Care for emergency department patients who have experienced domestic violence: a review of the evidence base. J Clin Nurs 2007;16:1736-48.

9. Ahmad I, Ali PA, Rehman S, et al. Intimate partner violence screening in emergency department: a rapid review of the literature. J Clin Nurs 2017;26:3271-85.

10. Wolff J, Cantos A, Zun L, Taylor A. Enhanced versus basic referral for intimate partner violence in an urban emergency

department setting. J Emerg Med 2017;53:771-7.

11. World Health Organization. Responding to intimate partner violence and sexual violence against women: WHO clinical and policy guidelines. WHO; 2013.

12. Argo A, Cucinella G, Calagna G, et al. Daphne II - Ve.R.S.O project: a new protocol for the management of sexual assault victims. It. J Gynecol Obstet 2012;4:141-53.

13. Iavicoli LG. Mandatory reporting of domestic violence: the law, friend or foe? Mt Sinai J Med 2005;72:228-31.

14. Davidov DM, Jack SM, Frost SS, Coben JH. Mandatory reporting in the context of home visitation programs: intimate partner violence and children's exposure to intimate partner violence. Viol Against Women 2012;18:595610.

15. Walker RM. Mandatory reporting of intimate partner violence: an ethical dilemma for forensic nurses. J Forensic Nurs 2017;13:143-6.

16. Pakieser RA, Lenaghan PA, Muelleman RL. Battered women: where they go for help. J Emerg Nurs 1998;24:16-9.

17. O'Doherty LJ, Taft A, Hegarty K, et al. Screening women for intimate partner violence in healthcare settings: abridged Cochrane systematic review and meta-analysis. BMJ 2014;348:g2913.

18. Mayer BW. Female domestic violence victims: perspectives on emergency care. Nurs Sci Q 2000;13:340-6.

19. Coker AL, Smith PH, Thompson MP, et al. Social support protects against the negative effects of partner violence on mental health. J Womens Health Gend Based Med 2002;11:465-76.

20. Ramsden C, Bonner M. A realistic view of domestic violence screening in an emergency department. Accid Emerg Nurs 2002;10:31-9.

21. Bugarín-González R., Bugarín-Diz C. Aspectos éticos en la atención sanitaria de la violencia de género. SEMERGEN Medicina de Familia 2014;40: 280-5.

22. Caralis PV, Musialowski R. Women's experiences with domestic violence and their attitudes and expectations regarding medical care of abuse victims. South Med J 1997;11:1075-80.

23. Gielen AC, O'Campo PJ, Campbell JC, et al. Women's opinions about domestic violence screening and mandatory reporting. Am J Prev Med 2000;19:279-85.

24. Freed PE, Drake VK. Mandatory reporting of abuse: practical, moral, and legal issues for psychiatric home healthcare nurses. Issues Ment Health Nurs 1999;20:423-36.

25. Pacheco R, Ruiz JM, Prieto JM, Jerónimo MV, Más A, Osuna E, et al. Análisis médico-legal de los partes de lesiones emitidos en un hospital general. Todo Hospital 1996;129:27-30.

26. Hirt MC, Costa MCD, Arboit J, et al. Social representations of violence against women for a group of rural elderly. Rev Gaucha Enferm 2018;38:e68209.

27. Montesinos A. Los partes médicos de lesiones en los procesos por violencia de género (II). Actualidad del Derecho Sanitario 2016; 240: 765-71.

28. Sarrión MT, Aracil C, Molina R, et al. Estudio descriptivo y valoración de la cumplimentación de los partes de lesiones generados en un servicio hospitalario de urgencias. Emergencias 1995;7:245-51.

29. Simon TR, Shattuck A, Kacha-Ochana A, et al. Injuries from physical abuse: National Survey of Children's Exposure to Violence I-III. Am J Prev Med 2018;54:129-32.

30. Berkowitz CD. Child abuse recognition and reporting: supports and resources for changing the paradigm. Pediatrics 2008;122:S10-2. 